\title{
Study on Community Co-management Model of San Jiangyuan Nature Reserves
}

\author{
Weijuan Feng \\ Department of Economics and Management, Ankang University, Ankang, Shanxi 725000, china \\ wjfeng720@163.com
}

\begin{abstract}
In order to solve the contradiction between protection and development of Sanjiangyuan Nature Reserves, the community co-management project was the first one introduced in the village of Cuochi in 2007. This paper intends to illustrate the superiority of developing community co-management based on ecological compensation. It explains from two aspects: the necessity of implementing community co-management and the improvement of relevant supporting measures in Sanjiangyuan Nature Reserves.
\end{abstract}

Index Terms - Sanjiangyuan Nature Reserves, Community Co-management, Ecological Compensation

Sanjiangyuan Nature Reserves is located in the hinterland of the Qinghai-Tibet Plateau, with a total area of $15.23 \times 104 \mathrm{~km}^{2}$, and is the largest area breeding many major rivers of Eurasia. It is a treasure trove of biodiversity resources, and is also a development area of wetland ecological resources, so is called "the third quarter" of the Earth. As located in the alpine zone which has harsh natural conditions, and primitive and fragile ecological environment, the ecological degradation is severe in recent years. In order to curb the deteriorating ecological environment, the initial ecological compensation measures and policies are established by the State in favor of ecological protection and construction of Sanjiangyuan region, such as returning grazing land to grassland, protection of natural forests, mineral resources taxes and compensation fees, and the implementation of the fiscal transfer payments and tax policy. SanJiangyuan region is included in the scope of national natural reserves, and clearly 7.507 billion yuan will be invested in the region for ecological protection and construction like returning grazing land to grassland, and enhancing the ecological compensation of forest resources and grassland resources. Up to July 2006, about 1.028 billion yuan had been invested to the major projects of ecological protection and construction in Sanjiangyuan Nature Reserves by the State. However, the establishment of nature reserves has reduced the income and assets and the limited opportunities for the development of local farmers and herdsmen, which deprived of their rights to use the natural resources reasonably in a large extent, and the existing ecological compensation fees are far insufficient to cover their loss, thus the contradictions between local farmers and herdsmen and nature reserves are intensifying. To solve this problem, in 2007, Sanjiangyuan Nature Reserves Soga-Quma River protection sub-area Cuochi village agreement protect project was started in Cuochi, Qumalai County, Yushu Tibetan Autonomous Prefecture. This was the first time to implement community co-management in ecological protection project by Saniiangyuan Nature Reserves Administration, Qinghai Province.

\section{The Concept of Community Co-Management}

Community co-management system dates back to the western countries, the first application was in the management of nature reserves by the government of Canada to coordinate the relationship between aboriginal and national parks [1]. The so-called community condominium refers to participating in the decision-making, implementation and evaluation process of management program of the reserves. It usually refers to that local community has certain specific duties for planning and using the natural resources, and also refers to that the community agrees with the sustainably use for resources without conflicting with the overall goal of protecting biodiversity, and its main goal is to combine biodiversity conservation with sustainable community development. [2]

\section{The Necessity for Community Co-Management in Sanjiangyuan Nature Reserves}

Community co-management as a management model that emphasizes participation is considered to be an effective method to solve the problem of resource protection by scholars[3]. However, conducting community co-management project has a special necessity in Sanjiangyuan Nature Reserves.

\subsection{Special geographical condition in Sanjiangyuan Nature Reserves needs the community co-management.}

Sanjiangyuan Nature Reserves is located in the hinterland of the Qinghai-Tibet Plateau, and sparsely populated for the local residents are mainly composed of Tibetan farmers and herdsmen,. However, the nature reserve area is vast, and the range needed to be protected is broad, the management staff alone is difficult to complete the important tasks of patrolling and monitoring. Most of nature reserves of our country lack of funds and personnel problems for a long time, which can not afford to hire more staff to engage in conservation efforts. On the one hand, local farmers and herdsmen have lost the opportunity to use natural resources to improve living standards, which exacerbated the conflict between the nature reserves; on the other hand, administrations suffer from lacking of personnel and being unable to complete administrative tasks. The implementation of community co-management in Cuochi village not only 
solved the management problem of lacking personnel and funds but also made full use of local human resources.

\subsection{Tibetan traditional cultures are in favor of implementing community co-management in Sanjiangyuan Nature Reserves. \\ Sanjiangyuan region is inhabited by Tibetan people, the} Tibetan population accounts for over $90 \%$ of the total population. Due to the harsh natural climatic conditions, the Tibetan people living long-term in this region form the traditional cultural values of reverence for life, the protection of nature, everyone is equal and animism[4]. They respect the land and all living things on the land, and believe that the relationship between man and nature is equal and mutualexchange. The natural world is seen as a whole, and therefore any form of damage is opposed. Thus, community co-management project in SanJiangyuan Nature Reserves has good mass and cultural foundation, which is a natural advantage that other nature reserves do not have.

\subsection{Community co-management can effectively protect the lives of the local residents.}

SanJiangyuan region is one of the poorest areas in China and Qinghai Province[5]. Establishment of nature reserves reduces the assets and limited development opportunities of the local farmers, reasonable use rights of resource of the community residents are deprived, and they often can not get adequate compensation, which greatly limits the development of economy. [6]Up to the end of 2005, 1756 family, 11373 ecological migrants had been relocated in SanJiangyuan region. Most of the farmers and herdsmen who did not relocate still live in the nature reserves, but the implementation of closed measures such as returning grazing land to grassland, close hillsides to facilitate afforestation, wetland protection, the feeding number of cattle and sheep was greatly reduced. At the same time, since the lack of basic knowledge and skills, their chances of engaging in non-agricultural industries and migrant work were also greatly reduced. According to the regulations of reserves, the pasture contract right is suspended after the relocation of the herdsmen. During grazing prohibition period, pastoralists can not return to their contracting pastures to engage in livestock production and operation activities and no longer enjoy the right to lease and transfer pasture. The population of SanJiangyuan region is mainly Tibetan herders, most of them long-term are engaged in pastoral livestock economy, and produce a single skill; and young and middle-aged herders generally have low level of cultural knowledge, and even some herders do not understand Chinese (according to the fifth province population census data, the illiteracy rate was 43.7\% in Yushu Prefecture, and 34.8\% in Goluo Prefecture) [7]. Therefore, it is relatively difficult to carry out follow-up industry in SanJiangyuan region, and farmers and herdsmen rely solely on compensation to sustain life is clearly not enough. According to "Nature Reserves Ordinance", scientific experiments, teaching internships, study tours, tourism and domestication, breeding of rare and endangered wild animals and plants activities can be engaged in the test area.
Implementation of community co-management, community residents do not have to leave the prairie to make a living, and can engage in a new animal husbandry, ecological industry, traditional handicrafts, and Tibetan style tourism under the guidance of the reserves and community management.

\section{Supporting Measures}

Community co-management in Cuochi village is still in the primary stage currently, and the co-management responsibility of community residents is mainly to patrol and monitor. For the effective implementation of community co-management project, solely rely on community farmers and herdsmen and the local government's autonomy is not enough, relevant auxiliary supporting measures are also needed.

\subsection{Legal protection}

Co-management lacking legal protection is fragile, [8] and to improve community co-management, legislation attempts can start from the following two aspects:

\subsubsection{Ecological compensation legislation}

Community co-management and ecological compensation have many commonalities and intersections. The goals of Cuochi village community co-management are, in addition to increase the diversity of wildlife and population quantity in the implementation area of the project; to improve monitoring and patrol capability of herdsman masses and environmental awareness, and also to further increase research investment, improve community management service capabilities and improve community education and sanitary condition, which obviously reduces the contradiction of environmental protection and economic development. Since our government took unilateral management model in nature reserves, it resulted in a lack of funds and single form of the nature reserves. Compared with other countries, China's investment in the nature reserves was grossly inadequate. For example, the United States has 398 national parks in 1997, and congressional annual budget of national parks is $\$ 1.26$ billion; the proportion of federal funds and self generating revenue of national parks is controlled in 3:1 in Canada. While in China, the total investment of construction of nature reserves over the years is about 1.59 billion yuan, and recently annual investment is 200 million yuan. [9] Therefore, the community co-management as a way of ecological compensation in ecological compensation legislation is a useful attempt. Ecological compensation in SanJiangyuan region somehow neglected the humanistic care towards the local farmers and herdsmen, but community co-management just achieved concerns for long-term development of farmers and herdsmen, and this kind of complementary can be reflected in the legislation.

\subsubsection{Legislation for SanJiangyuan Nature Reserves}

Currently, major laws and regulations in the management of SanJiangyuan Nature Reserves are "Environmental Protection Law", "Nature Reserves Ordinance", "Forest Law", "Wildlife Protection Law", "Water and Soil Conservation Law". But the natural conditions and ecological problems in 
SanJiangyuan Nature Reserves have large differences compared with other nature reserves in our country, thus it is difficult to take the special ecological and environmental conditions in SanJiangyuan region into account in national uniform legislation. Therefore, the quite fragile ecological environment in Sanjiangyuan region can not be effectively protected. [10] From 1989, a series of regulations of SanJiangyuan ecological protection has been formulated in Qinghai Province, however, these laws and regulations focused on the protection of ecological and social benefits in SanJiangyuan region from the national perspective, in the aspects of returning farmland to forest (grass) and ecological migrants, interests security and rational management of farmers and herdsmen of the community are not fully reflected. Thus, when designing the legislation of SanJiangyuan Nature Reserves, community co-management and ecological compensation should be put into the legislative system, and responsibilities and rights should be clearly defined and managed according to the laws; ownership issues are clearly divided and executed with scientific management; the rights of public participating, being informed, making decision, and democratic managing are clearly stipulated for community development.

\subsection{Policy support}

In the implementation process of community co-management in SanJiangyuan Nature Reserves, the state can develop a series of preferential policies:

\subsubsection{Tax policy}

Tax reduction and tax exemption preferential policies are applied for the engagement in non-pollution eco-industry of the community, which can encourage farmers and herdsmen to engage in green plant, new type livestock, traditional handicrafts, service industry and other related industries, so as to change production style and lifestyle.

\subsubsection{Employment policy}

For staff recruitment of nature reserves, priority should be gave to community residents who have some expertise and environmental awareness. In addition to the ecological compensation fees, appropriate payment should be paid for residents who are engaged in the work of patrol and monitor .

\subsubsection{Social security policy}

Together with ecological compensation, social security system will be established, and community residents are clearly included in the lowest social security system, so that they can enjoy the same treatment in employment, health care, schooling, pension insurance and other aspects with urban residents, and so as to achieve the coordinated development of ecology and economy. [11]

\subsection{Science and technology support}

On the one hand, utilizing technology to promote environment, the use of clean energy, recycling energy, and promoting recycle. On the other hand, absorbing experts and volunteers with professional knowledge and relevant environmental protection groups to take part in community co-management, engaging monitoring and training and education work of the community residents.

\subsection{Funds support}

A major obstacle is funds in community co-management, and now most of our projects of community co-management are based on funds provided by the international organizations, but these funds are ended after completing a certain goals, so the community co-management has become a short-term behavior, which is detrimental to the protection of ecology. In recent years, the State has increased the ecological compensation funds investment in SanJiangyuan Nature Reserves, but mainly is focused on the engineering and facilities construction; therefore the community co-management funds projects should be included in the budget, and make it a long-term government action. In addition, theoretically ecological compensation itself has a multi-level, comprehensive financing channel, such as the imposition of ecological compensation fees (taxes), the issue of ecological construction bonds or lottery, the establishment of compensation funds and market transactions, attracting international organizations, foreign government loans or donations. Protected areas and communities can either regard ecological compensation funds as a source of funds, or raise funds based on the ecological compensation channel.

Important ecological value of SanJiangyuan Nature Reserves is obvious, and community co-management is clearly an important way to solve the contradiction between conservation and development of SanJiangyuan region, Cuochi village has already taken the first step, and it requires the joint efforts of the whole society to accomplish this long-term work.

\section{References}

[1] Zhang Hong, Yang xinjun, Lishaogang. Revelation of Nature Reserve and Community Co-management on Our Country's Development of Eco-tourism-On Dawan Village in Mount Taibai. Human Geography, 2005(3).

[2] Wildlife Conservation Department of State Forestry Administration. Nature Reserve Community Co-management Guide. Beijing: China Forestry Publishing House, 2002:1.

[3] Zhang Hong, Yang Xinjun, Li Shaogang. Community Co-management: New Breakthroughs of Resource Management Model in Nature Reserves-Based on Dawan Village in Mount Taibai. China Population Resources and Environment, 2004, 14 (3):134-137.

[4] "SanJiangyuan Nature Reserves Ecological Protection and Construction" Editorial Board. SanJiangyuan Nature Reserves Ecological Protection and Construction. Qinghai: Qinghai People's Publishing House, April.2007, p32.

[5] "SanJiangyuan Nature Reserves Ecological Protection and Construction" Editorial Board. SanJiangyuan Nature Reserves Ecological Protection and Construction. Qinghai: Qinghai People's Publishing House, April.2007, p1.

[6] Zhang Xiaoni, Wang Zhongxian, Li Xue. Analysis of Limiting Factors of China Nature Reserves Community Co-management Model. Chinese Agricultural Science Bulletin, May.2007, 23(5).

[7] Zhang Hequan, Lu Qingzhang. Analysis and Consideration of Implementation of Ecological Migration in Qinghai San Jiangyuan Region. Qinghai Prataculture, Dec.2007, 16(4).

[8] Pomeroy R, Berkes F.Two to tango: the role of government in fisheries co-management. Marine Policy, 1997, 21(5):465-80.

[9] Liu Rui. Exploration of New Modes of Nature Protection and Harmonious Development of Community. Ecological Construction Compensation Mechanism and Policy Design Senior Seminar, 
Proceedings of Seminar, Chinese Society of Environmental Sciences, p129.

[10] "SanJiangyuan Nature Reserves Ecological Protection and Construction" Editorial Board. SanJiangyuan Nature Reserves Ecological Protection and Construction. Qinghai: Qinghai People's Publishing House, April.2007, p241-242.
[11] Zhang Li. On Ecological Compensation Mechanism and the Legal Protection of the Rights and Interests of Farmers and Herdsmen-Under the Perspective of SanJiangyuan Nature Reserves. Ecological Construction Compensation Mechanism and Policy Design Senior Seminar, Proceedings of Seminar, Chinese Society of Environmental Sciences, p51. 